\title{
Trigliserid Yüksekliği Olan Bir Hastada Akut Pankreatit Gelişimi: Olgu Sunumu
}

Acute Pancreatitis Development in a Patient with High Triglyceride: A Case Report Canan Akkuş $^{1}$ iD , Nurullah Damburacı ${ }^{\text {iD }}$, Hakan Yılmaz ${ }^{3}$ iD , Cevdet Duran ${ }^{4}$

1 İç Hastalıkları Kliniği, Uşak Eğitim ve Araştırma Hastanesi, Uşak/Türkiye 2 Genel Cerrahi Anabilim Dalı, Uşak Üniversitesi Tıp Fakültesi Uşak/Türkiye

3 Radyoloji Anabilim Dalı, Uşak Üniversitesi Tıp Fakültesi, Uşak/Türkiye

4 Endokrinoloji ve Metabolizma Hastalıkları Bilim Dalı, İç Hastalıkları Anabilim Dalı, Uşak Üniversitesi Tıp Fakültesi Uşak/Türkiye

\section{ÖzeT}

Akut pankreatit; pankreas bezinin inflamasyonu olup, hayatı tehdit edebilen ölümcül bir durumdur. Bir çok olguda kronik alkol kullanımı ve safra yolu hastalıkları etiyolojiden sorumlu olsa da nadiren hipertrigliseridemiye bağlıda akut pankreatit gelişebilir. Trigliserid düzeyleri arttıkça pankreatit gelişme riski artar ve 1000 mg/dl'yi geçen düzeylerde hastaların yaklaşık beşte birinde akut pankreatit geliştiği bildirilmiştir. Hipertrigliseridemi nedeniyle meydana gelen pankreatit tedavisinde oral alım kısıtlanması, yağdan fakir beslenme, insülin infüzyonu, heparin, lipit düşürücü ilaçlar, nadiren de plazmaferez kullanılabilir. Bu yazımızda daha önceden hiç lipit düşürücü ilaç tedavisi almamış ve 3 defa akut pankreatit gelişmiş bir hastayı sunduk. Akut pankreatit etiyolojisinde nadiren de olsa yüksek trigliserid düzeyleri sorumlu olabilir. Bu nedenle akut pankreatit gelişen tüm olgular lipit parametreleri açısından incelenmelidir.

Anahtar Kelimeler: hipertrigliseridemi, akut pankreatit, karın ağrısı

\section{ABSTRACT}

Acute pancreatitis is an inflammation of the pancreas and is a life-threatening condition. Although chronic alcohol use and biliary tract diseases are responsible for the etiology in many cases, acute pancreatitis may rarely develop due to hypertriglyceridemia. As triglyceride level increases, the risk of developing pancreatitis increases, and acute pancreatitis has been reported in approximately one-fifth of patients at levels exceed $1000 \mathrm{mg} / \mathrm{dL}$. In the treatment of pancreatitis caused by hypertriglyceridemia; oral feeding restriction, low-fat diet, insulin infusion, heparin, lipid-lowering drugs, and rarely plasmapheresis can be used. In this article, we present a patient who never received any lipid-lowering medication before and developed acute pancreatitis three times. High levels of triglycerides may rarely be responsible for the etiology of acute pancreatitis. Therefore, all cases with acute pancreatitis should be examined in terms of lipid parameters.

Keywords: hypertriglyceridemia, acute pancreatitis, abdominal pain

\section{Giriş}

Akut pankreatit (AP), pankreasın bezinin iltihabı olup, hafif ödematöz formdan ölüme sebep olabilecek ağır nekrotizan forma kadar değişik klinik yelpazede olabilir $(1,2)$. Uygunsuz olarak aktive olmuş pankreas enzimleri pankreas ve çevre dokuların öz sindirimine, sonuçta fokal ve yaygın nekroza neden olur. Günümüzde AP gelişen olgularda etiyolojide en sık sebep kronik alkol kullanımı, safra taşı ve safta yolu hastalıkları gibi patolojilerdir $(1,2)$. Trigliserid yüksekliği nadir sebeplerden sayılsa da trigliserid düzeyi $1000 \mathrm{mg}$ ve üzerindeki değerlerde pankreatit riski oldukça artmıştır (3). Trigliserid yüksekliği AP olgularının yaklaşık \%1-4'ünden sorumlu olup (3), $1000 \mathrm{mg} / \mathrm{dL}$ ve üzerinde trigliserid düzeyi olan olguların yaklaşık \%15-20'sinde AP gelişir (4).
Hipertrigliseridemili hastalarda hiperviskozite, iskemi, trigliseridlerin pankreatik lipaz ile hidrolizi sonucu ortaya çıkan çok fazla miktardaki serbest yağ asidinin meydana getirmiş olduğu lipotoksisite, buna bağlı inflamatuvar değişiklikler, asiner hücrelerde ve mikrovasküler membranlarda hasar AP gelişimine neden olur (4-6). Biz bu yazımızda daha önceden iki defa AP atağı geçirip, çok yüksek trigliserid düzeyleri olan ve hiç lipit düşürücü tedavi almayan AP'li bir hastayı sunduk.

\section{OLGU}

Kırk sekiz yaşında kadın hasta, karın ağrısı şikayeti ile acil servise başvurdu. Hikayesinde karın ağrısının acil servise başvurmadan 5-6 saat önce başladığı, esas olarak epigastrik

Yazışma Adresi/Address for Correspondence: Cevdet Duran, MD, Uşak Üniversitesi Tıp Fakültesi, i̇ç Hastalıkları Anabilim Dalı, Endokrinoloji ve Metabolizma Hastalıkları Bilim Dalı, 64200, Uşak/Türkiye

E-Posta/E-Mail: drcduran@gmail.com || Tel: +90 5334298585

Received/Geliş Tarihi: 25.06.2020 || Accepted/Kabul Tarihi: 24.12.2020

Bu Eser Creative Commons Atıf-Gayriticari 4.0 Uluslararası Lisansı Ile Lisanslanmıştır. This work is licensed under a Creative Commons

Attribution-NonCommercial 4.0 International License (CC BY-NC 4.0). 
bölgede olduğu, buradan tüm karına ve kuşak tarzında sırta yayıldığı, beraberinde bulantısı olduğu, ancak kusmadığı öğrenildi. Öz geçmişinde daha önceden kan yağlarında yükseklik olduğu söylendiği, ancak çok uzun yıllardır kan yağları tetkiki yapılmadığı, safra kesesinde taş olduğu, en sonuncusu 1,5 ay önce olmak üzere toplamda iki defa daha AP atağı geçirdiği ve hastanede yattığı öğrenildi. Sigara ve alkol kullanım öyküsü yoktu. Soy geçmişinde de özellik yoktu. Yapılan fizik muayenede boy $146 \mathrm{~cm}$, ağırlık $63 \mathrm{~kg}$, vücut kitle indeksi $29.56 \mathrm{~kg} / \mathrm{m}^{2}$ idi. Batın muayenesinde tüm kadranlarda yaygın hassasiyet ve istemli defans vardı. Karaciğer 3-4 cm orta sertlikte ele geliyordu. Perküsyonda karaciğer matite alanında artış dışında özellik saptanmadı, Traube alanı açıktı. Erüptif ksantoma yok idi. Laboratuvar tetkiklerinde amilaz 813 U/L (25-125) ve lipaz 1200 U/L (13$60 \mathrm{U} / \mathrm{L}$ ) bulundu (Tablo 1). Batın ultrasonografisinde (USG) karaciğer boyutunda artış $(210 \mathrm{~mm})$, parankiminde yağlanma ve dalak uzun aksında artış (135 mm), batın bilgisayarlı tomografi (BT)'de, pankreas korpus ve kuyruk kesimlerinde belirginleşen, mide korpusu posterioru düzeyine ve dalak hilusu komşuluğuna uzanan diffüz heterojen dansite artışı ve yaygın serbest sıvı saptandı ve akut pankreatitle uyumlu saptandı (Resim 1).

Resim 1. Kontrastlı abdomen BT inceleme de a) peripankreatik alanda yă planlarında kirlenme ve sIVI artışı b) pankreas gövde ve kuyruk kesiminde daha belirgin izlenen ödem ile uyumlu dansite azalması

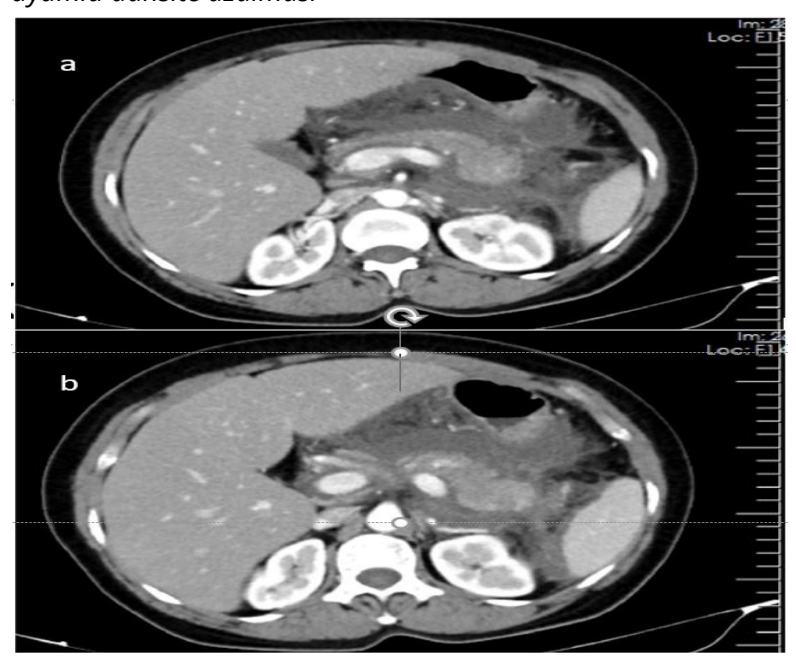

Yoğun bakıma alınan hastanın oral alımı kapatıldı. Daha önceden de iki defa AP geçiren hasta, hastalık etiyolojisi açısından yatışının ertesi günü bakılan trigliserid düzeyi 4036 mg/dL (N:50-200 mg/dL) bulundu. Tanı anında Ranson kriteri puanı 1 iken 48. saatte bu puan 0'a geriledi. Pankreatit açısında iV sıvı hidrasyonu sağlanan ve antibiyotik başlanan hastaya trigliserid yüksek gelmesi üzerine enoksaparin, insülin infüzyonu ve dekstroz infüzyonu, fenofibrat $267 \mathrm{mg}$ ve omega 3 kap 500 mg kapsül, 3×1 başlandı. Takiplerinde yatışının 2. günü karın ağrısı ve bulantısı gerileyen hasta, yatışının 3. günü yoğun bakımdan çıkarıldı, 4. günü trigliserid düzeyi 1022 mg/dL'ye lipaz düzeyi 106 U/L'ye geriledi. Laktesans testi negatif geldi. Küçük porsiyonlar halinde oral alım açıldı. Yatışının 5. günü insülin infüzyonu kesildi. Takiplerinde karında şişkinlik yakınması olan hastanın batın USG'de, karaciğer boyutunda artış (200 mm), parankiminde grade 1 yağlanma, safra taşı, safra çamuru, dalak boyunda artış (145 mm), pankreasta heterojenite ve korpus anteriorunda sIVI saptandı. Kontrol akciğer grafisinde sağda plevral efüzyon saptandı. Takiplerinde ertesi gün şişkinlik yakınması geriledi. Hasta poliklinik kontrolü önerilerek taburcu edildi.

Tablo 1. Hastanın tanı ve takiplerinde pankreas enzim ve lipit düzeyleri

\begin{tabular}{|cccccccc|}
\hline & A & L & TG & TK & LDL & HDL & VLDL \\
08.06 .20 & 439 & $>1200$ & & & & & \\
09.06 .20 & & 698 & 4036 & & & & \\
10.06 .20 & 116 & 330 & & & & & \\
11.06 .20 & 76 & 183 & 1412 & 345 & 27.9 & 34.7 & 282.4 \\
12.06 .20 & 52 & 106 & 1022 & & & & \\
13.06 .20 & & & & & & & \\
14.06 .20 & & & & & & & \\
15.06 .20 & 69 & 54 & 861 & & & & \\
16.06 .20 & & & 788 & 231 & 78 & 37.3 & 153.6 \\
17.06 .20 & & & 816 & & & & \\
18.06 .20 & & & 881 & & & & \\
22.06 .20 & & & 992 & & & & \\
\hline
\end{tabular}

A: $\operatorname{amilaz}(\mathrm{U} / \mathrm{L}), \mathrm{L}: \operatorname{lipaz}(\mathrm{U} / \mathrm{L}), \mathrm{TG}$ : trigliserid(mg/dL), $T K$ : total kolesterol(mg/dL), LDL: düşük dansiteli kolesterol(mg/dL), $H D L$ : yüksek dansiteli kolesterol(mg/dL), VLDL: çok düşük dansiteli kolesterol( $m g / d L)$

\section{SONUÇ}

Bu yazımızda safra taşı olan ve daha önceden iki defa AP atağı geçiren, ancak üçüncü AP atağında AP'nin trigliserid yüksekliğine bağlı olduğu anlaşılan bir kadın hastayı sunduk. Akut pankreatit tanısı Revize Atlanta Kriterlerine göre konmaktadır ve bu kriterlere göre hastada pankreatit yönünden tanısal bir şüphe yoktu (7). Akut pankreatit en sık kronik alkol tüketimi ve safra taşına bağlı gelişmektedir $(1,2)$. Hastanın daha önceki yatışlarında yapılan batın USG'sinde safra kesesinde taş olduğu raporlansa da bu başvurusunda yapılan acil batın USG'sinde sadece hepatosplenomegali saptandı, safra yollarıyla ilgili patoloji 
saptanmadı. Daha önceden safra taşı olan hastada AP etiyolojisi açısından ertesi gün istenilen trigliserid düzeyi çok yüksek saptandı. Ancak, hastanın takiplerinde yeniden yapılan kontrol batın USG'sinde safra çamuru ve milimetrik taşlar saptandı. Hastamızda safra taşı olsa da tipik bir biliyer kolik semptomları izlenmiyordu. Safra enzimleri ve bilirübin düzeyleri de normaldi. Ayrıca daha önceden iki defa daha pankreatit atağı geçirmesi ve hiç lipit düşürücü tedavi almamış olması nedeniyle, biz AP etiyolojisini safra taşına değil, çok yüksek trigliserid düzeylerine bağladık. Akut pankreatit atağı geçiren hastalarda safra taşı varlığında bile AP yapan diğer faktörlerin de mutlaka sorgulanması gerekir. Etiyolojinin eksik araştırılması bu hastada olduğu gibi tanının ve tedavinin gecikmesine, sonuç olarak da AP gibi yaşamı tehdit eder klinik durumlar gelişmesine neden olacaktır. Akut pankreatit gelişiminde hipertrigliseridemi nadir sebeplerden sayılsa da olguların yaklaşık \%1-4'ünden sorumludur (3). Trigliserid düzeyleri 1000 mg/dL üzerindeki değerlerde AP riski oldukça artmış olup (3), bu düzeyde trigliserid yüksekliği olan hastaların yaklaşık \%15-20'sinde AP gelişir (4).

Hastamızda olduğu gibi trigliserid düzeyi 1000 mg/dL ve üzerinde değerlerde genellikle ailesel hipertrigliseridemi düşünülmelidir. Hiperlipidemi sınıflandırması Fredrickson sınıflandırmasına göre yapılmaktadır (8,9). Bizim hastamızda trigliserid yüksekliğine bağlı akut pankreatit geliştiği için Fredrickson sınıflandırmasına göre Tip I, Tip IV veya Tip $\vee$ dislipidemi olabileceği düşünüldü $(8,9)$. Şiddetli trigliserid yüksekliğine sebep olan faktörler arasında lipoprotein lipaz eksikliği, lipoprotein lipaz gen mutasyonu, apolipoprotein CII eksikliği, glycosylphosphatidylinositol anchored high density lipoprotein binding protein 1 mutasyonu, LMF1 mutasyonu sayılabilir (10). Tip 1 dislipidemide lipoprotein lipaz eksikliği veya apo CII eksikliği nedeniyle lipoprotein lipazın aktive olmaması şilomikron yüksekliğine neden olur (8). Tip IV dislipidemide çok düşük dansiteli lipoprotein (VLDL) -kolesterol artışı, Tip V dislipidemide ise şilomikron ve VLDL artışı beraber izlenir (8). Dolaşımda trigliserid taşıyıcısı eksojen olarak şilomikronlar iken endojen olarak VLDL'dir. Tip 1 dislipidemide, diğer adıyla ailevi şilomikronemi, sıklıkla çocukluk döneminde başlar ve otozomal resesif geçiş gösterir, olgular herhangi bir provokatif faktör olmadan AP geliştirebilir. Buna karşın Tip IV ve Tip V dislipidemi durumunda herhangi bir çevresel ve hormonal faktör olmadan AP geliştirecek düzeyde hipertrigliseridemi yoktur. Tip IV dislipidemide diğer adıyla ailevi kombine hiperlipidemi çok sayıda gen ve çevresel faktörün etkileşimi sonucu ortaya çıkan kompleks genetik hastalık olup, genellikle erişkin döneminde AP ile kendini gösterir. Tip V dislipidemide, diğer adıyla primer mikst hipertrigliseridemi sık görülmekte olup, Tip I dislipidemide olduğu gibi AP gelişme riski yüksektir ve olgular genellikle erişkin yaşta tanı alırlar (8).

Bizim vakamızın çok yüksek trigliserid düzeyleriyle beraber pankreatit kliniği ve beraberinde hepatosplenomegalinin olması ön planda Tip I veya V dislipidemide düşündürdü. Trigliserid yüksekliği ile beraber VLDL kolesterol düzeylerinin hafif yüksek, yüksek dansiteli lipoprotein (HDL) kolesterol düzeylerinin düşük olması bizi daha çok Tip V dislipidemiye yönlendirdi. Ancak hiperlipidemisi için kesin tanı konulamadı. Laktesans testi negatifti ancak bu test yatışının 4. günü bakıldı ve trigliserid düzeyleri bu esnada zaten düşüktü. Hastanemizde teknik yetersizlik nedeniyle lipit elektroforezi, lipoprotein lipaz aktivitesi ve apo C-II düzeyi bakılamadı. Bu nedenle de ayırıcı tanı yapılamadı.

Hipertrigliserideminin tetiklediği AP olgularında hiperlipidemi tedavisinde diyet modifikasyonu, antihiperlipidemik ilaçlar, heparin, insülin, bazı vakalarda plazmaferez kullanılabilir (4). Hastamız AP nedeniyle ilk günden itibaren aç bırakıldı ve ancak ertesi gün trigliserid düzeyi çalışılabildi. Açlık, trigliserid düzeyleri üzerine oldukça düşürücü etkiye sahiptir ve bizim hastamızda bir günlük açlık sonrası bakılan trigliserid düzeyi 4036 mg/dL bulundu. Bu süre içerisinde lipoprotein lipaz enzim aktivasyonu için düşük molekül ağırlıklı heparin, insülin infüzyonu yapıldı. Omega-3 ve fenofibrat başlandı. Hastamızda yatışının 4. günü oral beslenmesi küçük porsiyonlar halinde ve yağdan fakir olarak açıldı.

Hafif (11) ve şiddetli AP'li (12) hastalarda erken beslenmenin konvansiyonel beslenmeye göre hastanede kalış süresini azalttığı gösterilmiştir. Bizim hastamızın takiplerinde yatışının 2. günü karın ağrısı ve bulantısı geriledi, yatışının 3. günü yoğun bakımdan normal odaya alındı, 4. günü trigliserid düzeyi 1022 mg/dl'ye ve lipaz düzeyi de 106 U/L'ye geriledi ve bunun üzerine küçük porsiyonlar halinde yağdan fakir diyetle oral alım açıldı. Yatışının 5. günü insülin infüzyonu kesildi. Şikayetleri gerileyen hastanın takiplerinde 
sağda plevral efüzyon saptandı, ancak takiplerinde asit ile beraber o da geriledi.

Pankreatit seyrinde erken aşamada hastaların \%62'sinde ekzokrin pankreas yetersizliği gelişirken, takiplerinde bu oranın \%35'e kadar düştüğü, şiddetli vakalarda hafif vakalara göre iki kat daha fazla olduğu ve en sıklıkla da pankreas nekrozu gelişen olgularda ve alkole bağrı pankreatit gelişen olgularda olduğu bildirilmiştir (13). Tekrarlayan AP ataklarında bu risk daha fazladır. Bizim hastamızın takiplerinde ishal yakınması yoktu ancak, pankreas yetersizliği açısından da malabsorbsiyon testlerinin yapılması planlandı.

Sonuç olarak AP sebepleri arasında hipertrigliseridemi nadir fakat önemli yer tutar. Hastalarda safra taşı olsa bile AP gelişen hastalarda mutlaka trigliserid düzeyleri ölçülmelidir. Buna ilaveten, trigliserid düzeyi yüksek hastalarda pankreatit gelişmeden alınacak diyet, egzersiz ve ilaç tedavisi gibi tedbirler bu hastalarda pankreatit gelişimini önleyebilir.

Etik; Bu yazıda sunulan olgu için sunulan bilgilerin akademik amaçlı kullanımı hakkında detaylı bilgileri de içeren imzalı "Bilgilendirilmiş onam formu" alınmıştır.

Ethics; For the case presented in this article, a signed "informed consent form" was obtained, which includes detailed information about the use of the information presented for academic purposes.

Yazar katkı durumu; Olgunun tanı ve takip süreci; CA, ND, $\mathrm{HY}, \mathrm{CD}$, tedavi süreci; $\mathrm{CA}, \mathrm{ND}, \mathrm{HY}, \mathrm{CD}$, Literatür taraması; $\mathrm{CA}$, $N D, H Y, C D$, yazım aşaması; $C A, N D, H Y, C D$

Author contribution status; The concept of the study; CA, $N D, H Y, C D$, design; $C A, N D, H Y, C D$, literature review; $C A$, $N D, H Y, C D$, collecting and processing data; $C A, N D, H Y, C D$, statistics; $C A, N D, H Y, C D$, writing phase; $C A, N D, H Y, C$

Yazarlar arasında çıkar çatışması yoktur.

The author declares no conflict of interest.

Finansal Destek: yoktur / Funding : none

doi: https://doi.org/10.33713/egetbd.757751

\section{KAYNAKLAR}

1. Karne S, Gorelick FS. Etiopathogenesis of acute pancreatitis. Surg Clin North Am. 1999;79:699-710.

2. Testoni PA. Acute recurrent pancreatitis: Etiopathogenesis, diagnosis and treatment. World J Gastroenterol. 2014;20:1689116901.

3. Zhang XL, Li F, Zhen YM, Li A, Fang Y. Clinical Study of 224
Patients with Hypertriglyceridemia Pancreatitis. Chin Med J (Engl). 2015;128:2045-2049.

4. Valdivielso P, Ramírez-Bueno A, Ewald N. Current knowledge of hypertriglyceridemic pancreatitis. Eur J Intern Med. 2014;25:689-694.

5. Kimura W, Secknus R, Fischbach W, Mössner J. Role of phospholipase A2 in pancreatic acinar cell damage and possibilities of inhibition: studies with isolated rat pancreatic acini. Pancreas. 1993;8(1):70-79.

6. Thompson GR. Primary hyperlipidaemia. Br Med Bull. 1990;46:986-1004.

7. Banks PA, Bollen TL, Dervenis $C$, et al. Classification of acute pancreatitis--2012: revision of the Atlanta classification and definitions by international consensus. Gut. 2013;62:102-111.

8. Fredrickson DS. An international classification of hyperlipidemias and hyperlipoproteinemias. Ann Intern Med. 1971;75:471-472.

9. Verma N. Introduction to hyperlipidemia and its treatment: a review. Int J Pharm Res. 2016;9:6-14

10. Hegele RA, Ginsberg HN, Chapman MJ, et al. The polygenic nature of hypertriglyceridaemia: implications for definition, diagnosis, and management. Lancet Diabetes Endocrinol. 2014;2:655-666.

11. Zhang J, Zhu S, Tan D, Ma A, Yang Y, Xu J. A meta-analysis of early oral refeeding and quickly increased diet for patients with mild acute pancreatitis. Saudi J Gastroenterol. 2019;25:14-19.

12. Zhao XL, Zhu SF, Xue GJ, et al. Early oral refeeding based on hunger in moderate and severe acute pancreatitis: a prospective controlled, randomized clinical trial. Nutrition. 2015;31:171-175.

13. Huang W, de la Iglesia-García D, Baston-Rey I, et al. Exocrine Pancreatic Insufficiency Following Acute Pancreatitis: Systematic Review and Meta-Analysis. Dig Dis Sci. 2019;64:1985-2005. 